Int. J. Dev. Biol. 62: 383-386 (2018)

https://doi.org/10.1387/ijdb.180088fs

\title{
Can broken hearts be mended? Ken Poss, a pioneer on heart regeneration research
}

\author{
NADIA MERCADER ${ }^{*, 1}$ and FLORENCI SERRAS ${ }^{*, 2}$ \\ ${ }^{1}$ Institute of Anatomy, University of Bern, Bern, Switzerland and \\ ${ }^{2}$ Department of Genetics, Institute of Biomedicine (IBUB), University of Barcelona, Barcelona, Spain
}

\begin{abstract}
In 2002, Ken Poss discovered that zebrafish, at that time an emerging vertebrate model organism in basic research, were able to regenerate their heart upon resection of the ventricular apex. This finding set in motion a new field of research on heart regeneration, which has recently expanded in other model organisms including mammals. We interviewed Ken Poss to find out more about his motivation and vision for the future of tissue regeneration research.
\end{abstract}

KEY WORDS: heart regeneration, cardiomyocyte, fin regeneration, progenitor cell, organ regeneration, zebrafish

Kenneth D. Poss is a James B. Duke Professor in the Department of Cell Biology and Director of the Regeneration Next Initiative at Duke University Medical Center. He received his B.A. in Biology from Carleton College in 1992, and his Ph.D. in Biology from MIT in 1998 for research with Susumu Tonegawa. Dr. Poss was a postdoctoral fellow with Mark Keating at the University of Utah and Boston Children's Hospital. In 2003, he initiated his research program at Duke, and since then he has spearheaded the investigation of tissue regeneration in the zebrafish model system. He discovered heart regeneration in zebrafish, establishing an important model of robust innate cardiac repair (Poss et al., 2002). Since then he has been a leader in the field at both conceptual and technological levels (Karra and Poss, 2017; Tornini and Poss, 2014). His laboratory has identified key cellular (Kikuchi et al., 2010), signaling (Lepilina et al., 2006), and gene regulatory events (Goldman et al., 2017) underlying regeneration of heart muscle and other tissues in zebrafish, described in dozens of primary research reports. In the process, his group has introduced many tools to interrogate regeneration and morphogenesis in zebrafish, including inducible single and multicolor cell lineage tracing (Gupta and Poss, 2012), cell-specific ablation injury models (Wang et al., 2011), transgenic reporter and loss-of-function strains, live imaging platforms, and genetic and chemical screening platforms. The description of regeneration enhancer elements in zebrafish that can also direct gene expression in injured mammalian tissue is one of his latest findings, illustrating how animal models can reveal universal injury response mechanisms (Kang et al., 2016). His research goal is to elucidate the mechanisms of vertebrate tissue regeneration, and to use this information to improve the poor regenerative capacity of human tissues like the heart, spinal cord and limbs.

To start, what do you think are the main goals in regeneration research today?

First, to understand how it works. Genetic fate-mapping and live imaging technologies have revealed or are revealing the key cell sources and behaviors in regenerating tissue. In an age of rapidly evolving genome-editing techniques, the field is in a better position than ever to reveal key triggers for regeneration events, and also, the DNA regulatory events and post-transcriptional events that control the presence of these triggers after an injury. Second, all of us who study regeneration want to know why it happens. What explains the different capacities for regeneration among tissues and species, how might these differences have evolved through genetic change, and why might this disparity exist?

\section{What triggered your interest in organ regeneration?}

Beyond general fascination with regeneration as a phenomenon since I was young, I became serious about regeneration research 20 years ago. It was (and still is) a challenging nut to crack, and at the time had not been aggressively pursued using genetics. The fact that there was (and is) so much yet to learn about what controls tissue regeneration was both intimidating and attractive. Also, it is a highly visual science - that is, data are often expressed as images, which l've always liked.

\section{Which scientists or non-scientists have been a source of inspiration to you?}

It is hard but I will limit myself here. First, my lab members over

\footnotetext{
*Address correspondence to: Florenci Serras. Department of Genetics, Institute of Biomedicine (IBUB), University of Barcelona, Barcelona, Spain.

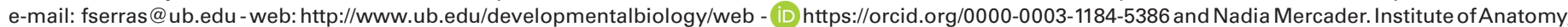

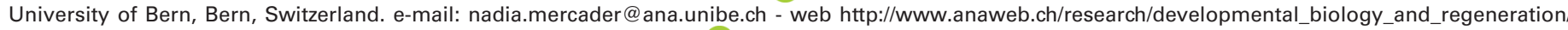
group_members/detail/index_eng.php?id=449 - Fax: +413163138 07. - (iD) https://orcid.org/0000-0002-0905-6399
}

Submitted: 9 March, 2018; Accepted: 12 March, 2018.

ISSN: Online 1696-3547, Print 0214-6282

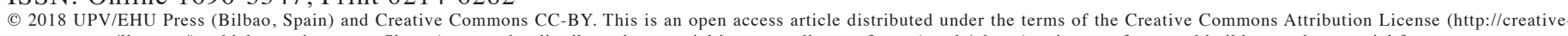

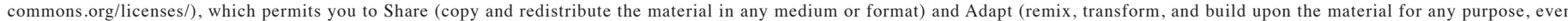

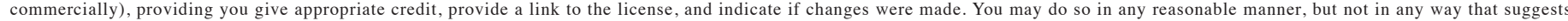
the licensor endorses you or your use. Printed in Spain 


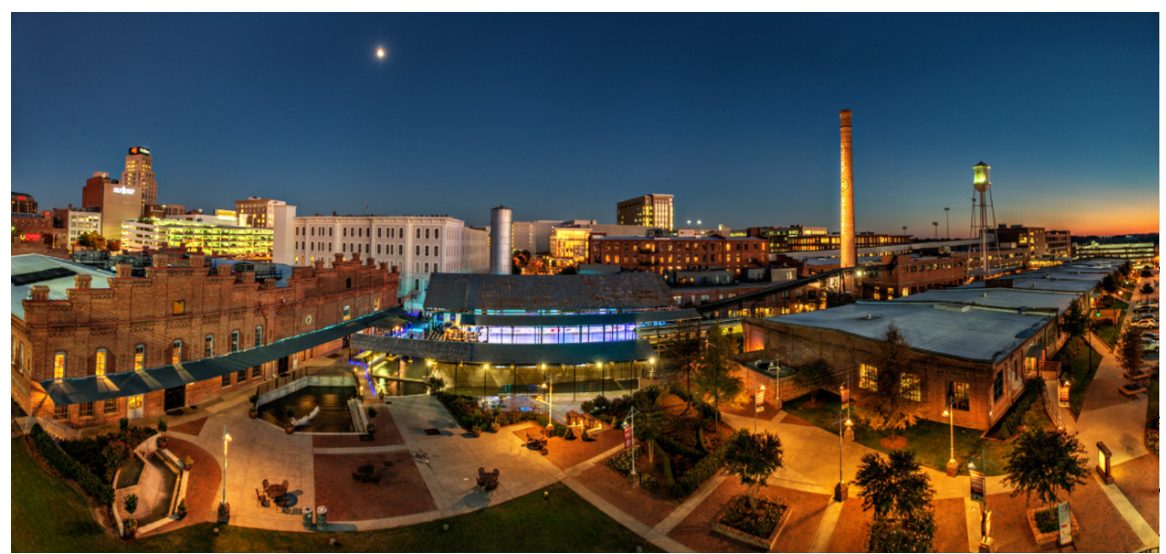

Fig. 1 Durham, North Carolina, USA. Duke University is located in Durham, North Carolina, a mid-sized city of progressive thinking, diverse, low-cost living options, mild weather and revitalized nightlife. (Image: Scott Faber).

the past 14-plus years at Duke. These talented, creative people make the discoveries, and my role is to provide the environment, resources, and some guidance. I have been very fortunate to explore with them, and in such a wonderful part of the world to live and work. I was also lucky myself to train with two pioneering scientists. Susumu Tonegawa, my graduate advisor, trained as a molecular biologist and as a young PI solved the problem of antibody diversity, and since then has made seminal contributions to how memories are acquired and stored. Mark Keating, my postdoctoral advisor, trained as a cardiologist and studied receptor signaling before discovering the genetic basis of human cardiac arrhythmias and other cardiovascular diseases as a young PI. As an established PI, Mark switched his attention to tissue regeneration and oversaw an exciting program for many years. Both scientists made risky decisions to alter directions multiple times over their careers, emerging in each case with great success.

Tell us about how and when you started in science. And...why with zebrafish?

Science is ideal for the creative introvert. I like the pace, the means of expression, the communities, and the goals of biomedical research. I feel lucky to have found such a match. I didn't start

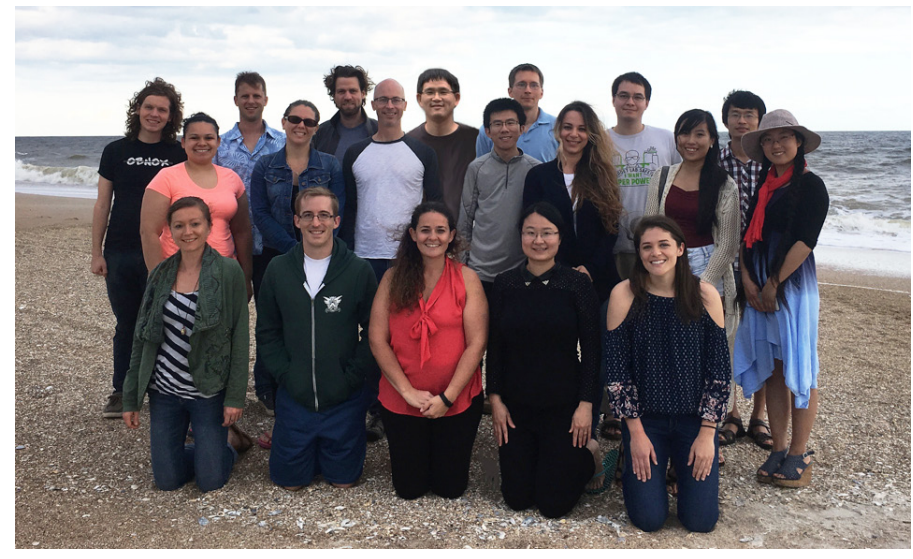

Fig. 2. Poss lab retreat. A lab retreat at beach houses on the nearby Atlantic Ocean for 2 days of science, fun and team building. (Image: Amy Dickson). with zebrafish, but rather with in vitro synthesized RNAs and proteins in a small lab run by John Tymoczko at Carleton College in Minnesota. I was one of 3 students in one of John's seminar classes and he offered all of us a chance to do science in his lab - I took the bait and haven't looked back! Toward the end of my thesis work at MIT I became interested in zebrafish. Two of my graduate student colleagues were screening for viral insertions that disrupt embryonic development in zebrafish in the lab next door to ours. I thought their system was great and could allow me to apply genetics to a fascinating problem like regeneration. Mark's lab did not have zebrafish, but Alex Nechiporuk (a graduate student at the time and now faculty at OHSU in Portland, Oregon) and I started raising fish in the lab with guidance from Steve Johnson at Washington University and our colleagues at University of Utah. A few years later and after a laboratory move to Boston, I started thinking about whether zebrafish could regenerate their hearts and started some exploratory experiments with Lindsay Wilson, a very talented research technician working with me at the time. Breaking a few fish hearts let to a lot of interesting research questions.

\section{Let's talk about fins. Why fins?}

Why not fins? Fins are the original tissue studied for regenerative properties in fish, going back over two centuries. An intricately patterned skeleton is regenerated consistently and rapidly, and their regeneration can be readily quantified. As an external tissue, fins are amenable to imaging at single-cell resolution, and as fins are not required for viability one can screen for mutants. It's a great tissue for dissecting general concepts in regeneration, like patterning and positional memory.

\section{Adult zebrafish hearts can regenerate, mammalian hearts cannot. To what extent do you think size matters?}

I think of it more as grays than black and white. Zebrafish vigorously regenerate heart muscle, even if $50 \%$ or $60 \%$ of all muscle is destroyed, though not "perfectly". Mammalian models regenerate heart muscle poorly but seem to have some measurable capacity to replace lost muscle cells. This is important when you think of the possibility of regenerative therapies. For zebrafish, it is true that their single cardiac ventricle is about one microliter. So, the amount of muscle they regenerate is trivial compared to the hundreds of millions of cardiomyocytes lost in a human myocardial infarct. However, when one considers scale and proportion, what zebrafish do is most impressive - a high proportion of their cardiomyocytes are activated to divide after injury.

\section{Will it be possible to regenerate a human heart some day? Or is it a dream?}

Yes, and yes. Getting more people to survive the event has been the first key step, but it means there are more people with increased susceptibility to heart failure. So the incentive for regenerative therapies for the heart has increased. The strategies to effect muscle regeneration are clever though still inefficient. More basic knowledge of heart regeneration from systems like zebrafish, combined with advances to make and deliver factors or cells. 

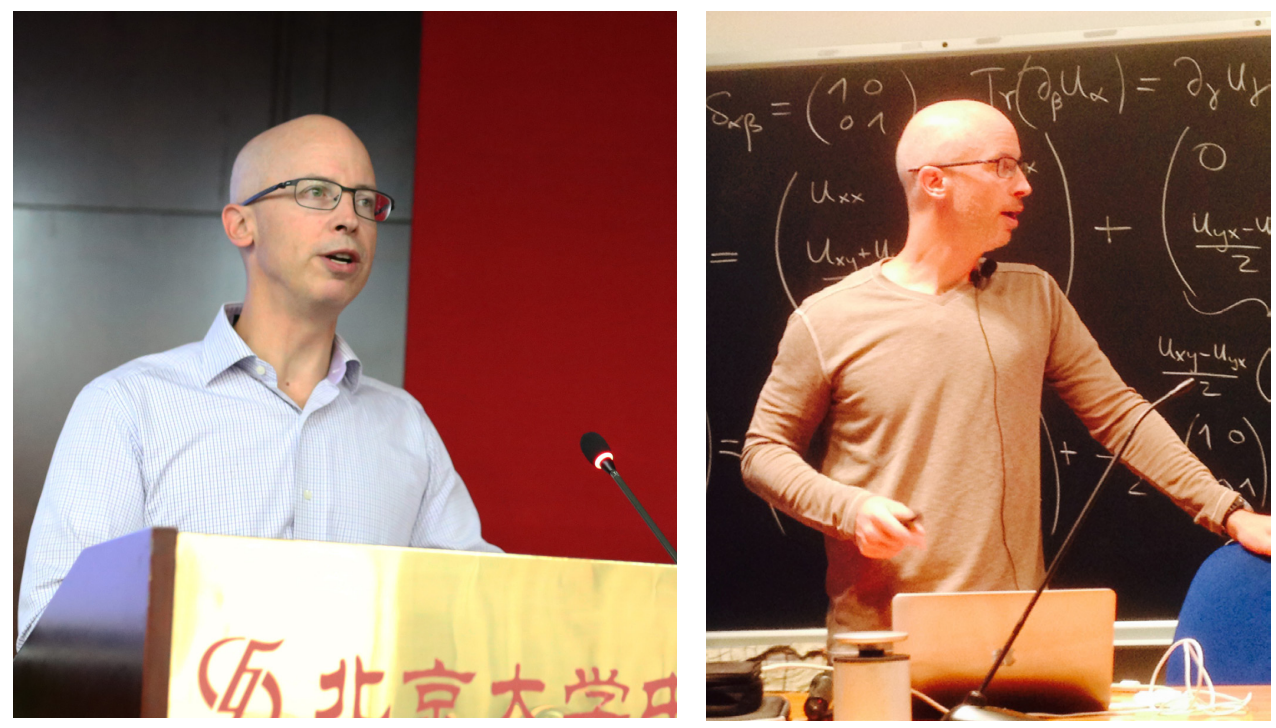

Fig. 3 (Left). Spreading the word about regeneration. Excitement about regenerative biology and medicine is growing internationally. Many meetings take place on the topic each year. (Image: Chenglu Xiao).

Fig. 4 (Right). Teaching regeneration. Students at all levels are hungry to learn about tissue regeneration. (Image: Stefano DiTalia).

There is a lot of bad stuff going on in an ischemic myocardial infarct that needs to be overcome, but yes, I see the field getting there.

\section{How can a human heart survive with a cardiomyocyte turnover of 0.3 to $1 \%$ per year?}

Cardiomyocytes are pretty amazing cells that can last a lifetime. What endows such longevity is important to understand. Beyond that, the heart is well known for its compensatory physiological responses. These resilience properties and others are key and it is likely they differ among people.

\section{Do you think that all cardiomyocytes have an equal} capacity for proliferation? What about stem cells vs. progenitors as sources of cardiomyocytes?

In zebrafish, evidence indicates that cardiomyocytes in the ventricle have a similar capacity for proliferation upon injury. In mammals, there is likely more heterogeneity. Recent findings indicate that mononucleate, diploid cardiomyocytes, which are a minority cell population in adult mammals, are more capable of proliferating upon injury than polyploid cardiomyocytes. This and other bases of heterogeneity are important to study, as it could reveal new markers and ways to target cells with higher regenerative capacity.

Do you think the capacity of cardiomyocyte division is a cell-autonomous property and to what extent might it be influenced by the environment?

A combination of both. The threshold of competency for cell cycle entry and division appears to be lower in zebrafish than mammals. At the same time, the injury environment is likely more conducive to regeneration. I feel it is important to study both of these components.

Why is it that the heart is pretty resistant to tumors? Is there a link with its poor regenerative ability?

Tumors generally do not originate from cardiomyocytes. One has to imagine a link to the fact that these cells have such a low rate of turnover or natural tendency to divide in adult mammals.
What could regeneration research learn from cancer biology? And what could cancer biology learn from regeneration research?

Cancer is insidious in large part due to the genetic and epigenetic changes that malignantcells have undergone to promote relentless division, migration, and invasion. Regenerating cells also undergo sudden division, migration, and invasion, presumably occurring entirely from epigenetic changes. However, regeneration involves a return to quiescence that, if fully explored and understood, could be illuminating in considering approaches to cancer.

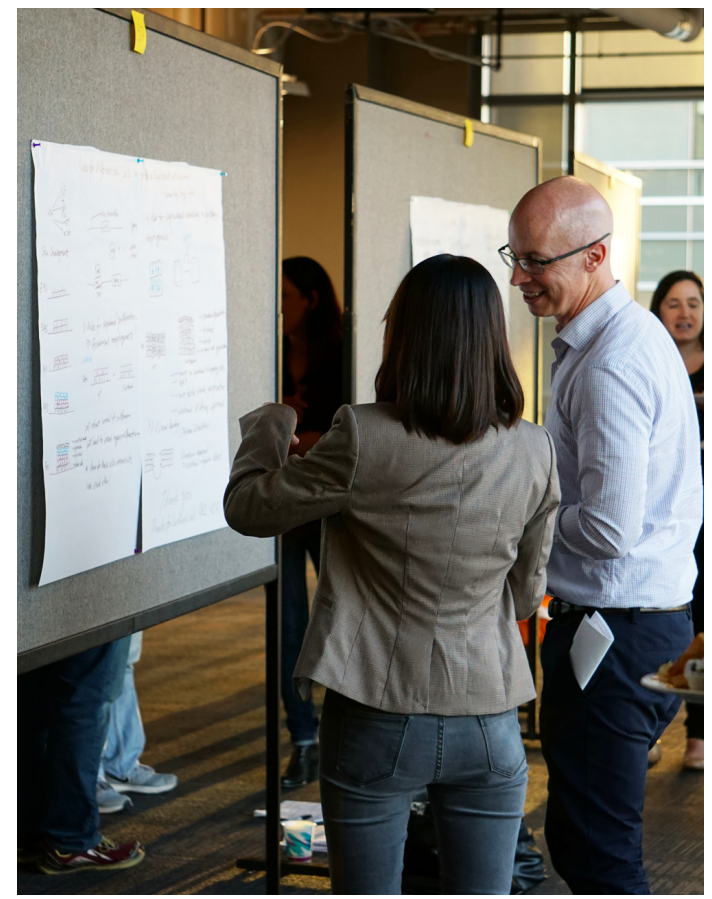

Fig. 5. Regeneration Next. Ken Poss directs a campus-wide initiative at Duke called Regeneration Next, with goals to grow, support and synergize faculty and trainees to enhance discovery and application in tissue regeneration. (Image: Amy Dickson). 


\section{Regarding the future, how can zebrafish continue to contribute to the field of organ regeneration?}

The future of the model system looks bright. There are many hundreds of labs around the world, forming a large, close, and collaborative community. The research tools are evolving wonderfully such that molecular geneticists can generate mutant and transgenic lines at will. And, zebrafish will always have profound regenerative abilities to study. It is great to see that more and more labs that have used zebrafish to study embryogenesis are expanding their outlooks to probe regeneration.

\section{Do you see organoids replacing animal models in regeneration research?}

Replacing? No. Complementing? Yes, this is a great development and it will be exciting to see how intricate and mature these organoids ultimately become.

\section{What would be your advice for an early stage career fellow that wants to start a project on organ regeneration?}

It's a great time to enter the field, though very different than from when I did 20 years ago. Model systems are well-developed and readily manipulated. Genome-editing allows consideration of myriad animals as new models. On the academic side, there are still many institutions in need of great scientists to run research programs in tissue regeneration, with some places even opening up new departments on this topic. In the pharmaceutical space, imagine being able to effectively drug regeneration of heart muscle, knee cartilage, or striatal neurons(!) There most definitely are opportunities and incentives in this area for young scientists with ambitious goals.

\section{References}

GOLDMAN JA, KUZU G, LEE N, KARASIK J, GEMBERLING M, FOGLIAMJ, KARRA R, DICKSON AL, SUN F, TOLSTORUKOV MY, POSS KD (2017). Resolving Heart Regeneration by Replacement Histone Profiling. Dev Cell 40: 392-404.e5.

GUPTA V, POSS KD (2012). Clonally dominant cardiomyocytes direct heart morphogenesis. Nature 484: 479-484.

KANG J, HUJ, KARRAR, DICKSONAL, TORNINI VA, NACHTRAB G, GEMBERLING M, GOLDMAN JA, BLACK BL, POSS KD (2016). Modulation of tissue repair by regeneration enhancer elements. Nature 532: 201-206.

KARRA R, POSS KD (2017). Redirecting cardiac growth mechanisms for therapeutic regeneration. J Clin Invest 127: 427-436.

KIKUCHI K, HOLDWAY JE, WERDICH AA, ANDERSON RM, FANG Y, EGNACZYK GF, EVANST, MACRAECA, STAINIERDY, POSS KD (2010). Primary contribution to zebrafish heart regeneration by gata4(+) cardiomyocytes. Nature 464:601-605.

LEPILINA A, COON AN, KIKUCHI K, HOLDWAY JE, ROBERTS RW, BURNS CG POSS KD (2006). A dynamic epicardial injury response supports progenitor cell activity during zebrafish heart regeneration. Cell 127: 607-619.

POSS KD, WILSON LG, KEATING MT (2002). Heart regeneration in zebrafish. Science 298: 2188-2190.

TORNINI VA, POSS KD (2014). Keeping at arm's length during regeneration. Dev Cell 29: 139-145.

WANG J, PANÁKOVÁ D, KIKUCHI K, HOLDWAY JE, GEMBERLING M, BURRIS JS, SINGH SP, DICKSON AL, LIN Y-F, SABEH MK, WERDICH AA, YELON D, MACRAE CA, POSS KD (2011). The regenerative capacity of zebrafish reverses cardiac failure caused by genetic cardiomyocyte depletion. Development 138 : 3421-3430. 


\section{Further Related Reading, published previously in the Int. J. Dev. Biol.}

Reptile genomes open the frontier for comparative analysis of amniote development and regeneration Marc Tollis, Elizabeth D. Hutchins and Kenro Kusumi

Int. J. Dev. Biol. (2014) 58: 863-871

https://doi.org/10.1387/ijdb.140316kk

Cell-based cardiovascular repair and regeneration in acute myocardial infarction and chronic ischemic cardiomyopathy - current status and future developments

Christian Templin, Thomas F. Lüscher and Ulf Landmesser

Int. J. Dev. Biol. (2011) 55: 407-417

https://doi.org/10.1387/ijdb.103219ct

\section{Epiblast-derived stem cells in embryonic and adult tissues}

Maria P. De-Miguel, Francisco Arnalich-Montiel, Pilar Lopez-Iglesias, Alejandro BlazquezMartinez and Manuel Nistal

Int. J. Dev. Biol. (2009) 53: 1529-1540

https://doi.org/10.1387/ijdb.072413md

Induction and patterning of the cardiac conduction system

David J Pennisi, Stacey Rentschler, Robert G Gourdie, Glenn I Fishman and Takashi Mikawa Int. J. Dev. Biol. (2002) 46: 765-775

http://www.intjdevbiol.com/web/paper/12382942

Regulation of neural crest cell populations: occurrence, distribution and underlying mechanisms

$\mathrm{J} \mathrm{L}$ Vaglia and B K Hall

Int. J. Dev. Biol. (1999) 43: 95-110

http://www.intjdevbiol.com/web/paper/10235385

Heart development and regeneration in urodeles

A W Neff, A E Dent and J B Armstrong

Int. J. Dev. Biol. (1996) 40: 719-725

http://www.intjdevbiol.com/web/paper/8877445

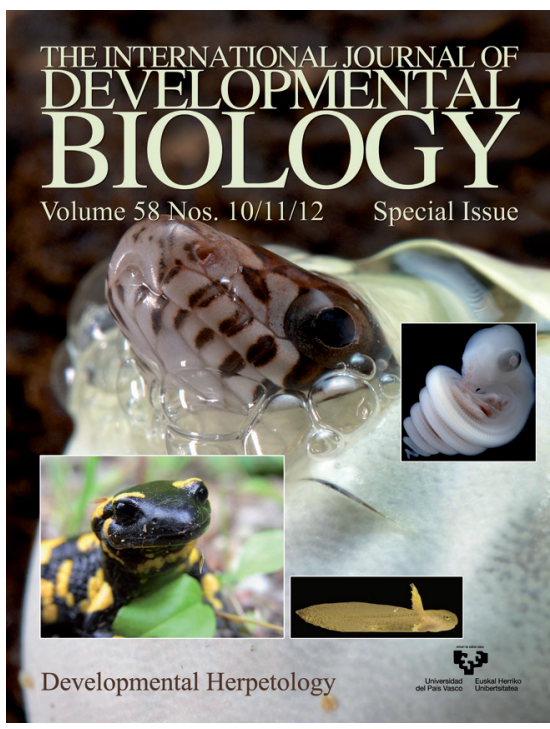

5 yr ISI Impact Factor $(2016)=2.421$

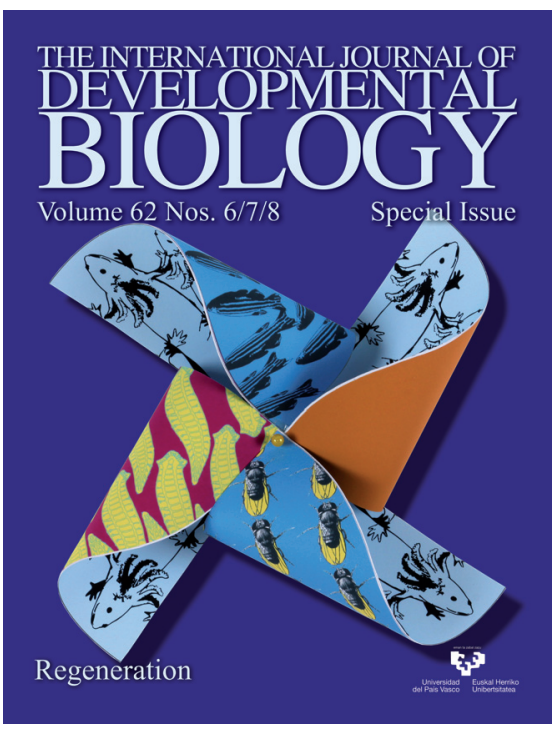

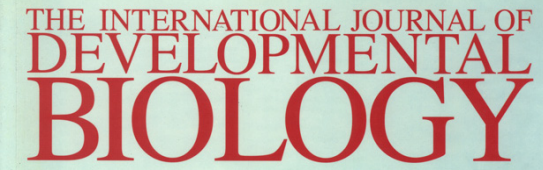

Volume 40 No. 4 August 1996
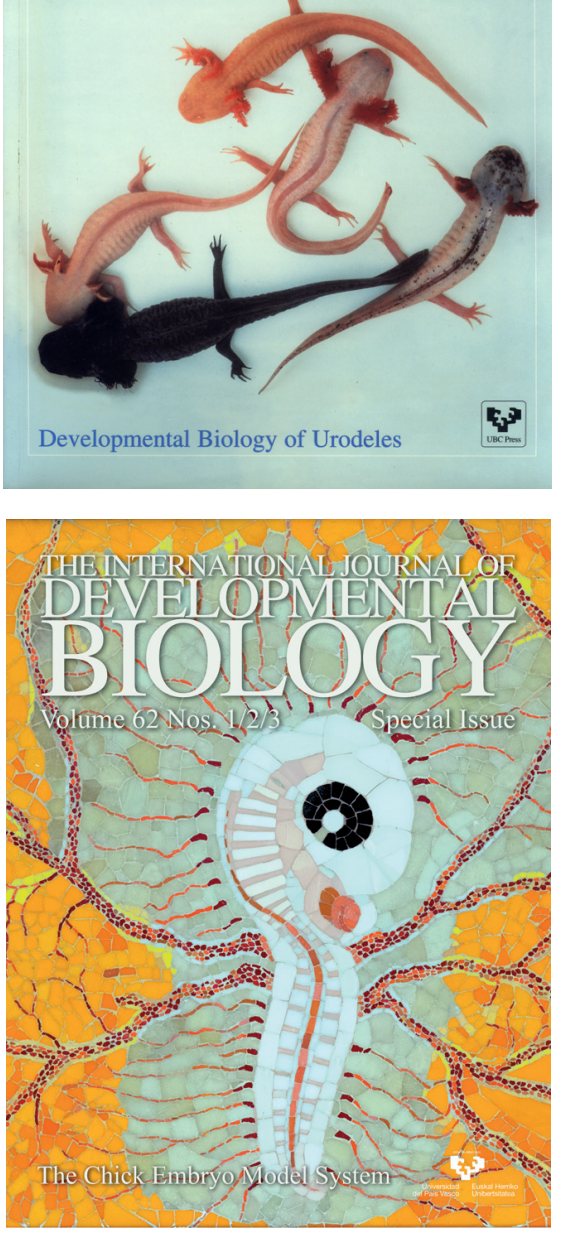